\title{
S0820204
}

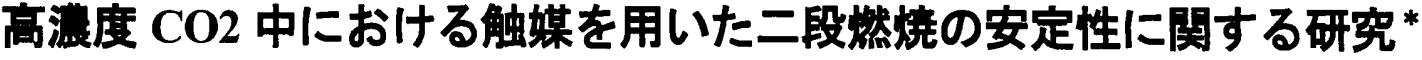

\author{
長井 登志憲 ${ }^{* 1}$, 植田 利久 ${ }^{* 2}$, 横森 剛 ${ }^{* 2}$
}

\section{The stability of two-staged catalytic combustion in highly concentrated $\mathrm{CO2}$}

\author{
Toshinori NAGAI ${ }^{* 1}$, Toshihisa UEDA ${ }^{* 2}$ and Takeshi YOKOMORI ${ }^{* 2}$ \\ ${ }^{* 1}$ Keio Univ. Graduate School of Science and Technology, \\ 3-14-1, Hiyoshi, Kohoku-ku, Yokohama, Kanagawa, 223-8522, Japan
}

\begin{abstract}
Oxy-fuel combustion is an attractive method of reducing $\mathrm{CO}_{2}$ emission. In oxy-fuel, the high concentrated $\mathrm{CO}_{2}$ destabilizes the combustion. In this study, the catalytic pre-combustion was used for the improvement of the flame stability in highly concentrated $\mathrm{CO}_{2}$. The experiments and numerical calculation were performed to elucidate the influence of the catalytic pre-combustion on the flame stabilization. The burner was consisted of a Pt catalyst pipe with $5 \mathrm{~mm}$ in diameter confined by a quartz tube with $40 \mathrm{~mm}$ in diameter. The $\mathrm{CH}_{4} / \mathrm{O}_{2} / \mathrm{CO}_{2}$ mixture was jetted out from the Pt catalyst pipe. The mixture inlet velocity $V$ and equivalence ratio $\phi$ were varied. For comparison, the $\mathrm{CH}_{2} / \mathrm{O}_{2} / \mathrm{N}_{2}$ mixture was also used. In the numerical calculation, a two-dimensional axisymmetric model was implemented into the CFD code ANSYS-Fluent 14.0. In the experiment, the blow off velocity of the flame in the $\mathrm{CH}_{4} / \mathrm{O}_{2} / \mathrm{CO}_{2}$ mixture showed lower than that in the $\mathrm{CH}_{4} / \mathrm{O}_{2} / \mathrm{N}_{2}$ mixture even with and without the catalytic combustion. The blow off velocity with the catalytic combustion was lower than that without the catalytic combustion at the lower equivalence ratio. This is because the catalytic combustion consumed reactants, so that the reactants were insufficient to sustain the flame at the downstream side of the catalyst. On the other hand, blow off velocity with the catalytic combustion is higher than that without the catalytic combustion at the higher equivalence ratio. This is because the high temperature mixture including the high reactivity intermediates generated by the catalytic combustion stabilized the gas phase reaction.
\end{abstract}

Key Words : Catalyst combustion, Flammability Limit, Stability, Oxy-fuel, Numerical Simulation

\section{1. 锖}

近年 $\mathrm{CO}_{2}$ の排出量削減対策として, 二酸化炭素回収貯留技術(CCS)が注目を浴びている. CCS では排出される $\mathrm{CO}_{2}$ を回収し地中や海洋中に眝留することで大幅な $\mathrm{CO}_{2}$ 排出量の削減が可能となる. そして, その CCS 技術の中 でも大型 $\mathrm{CO}_{2}$ 排出源に適用する技術として oxy-fuel 燃焼法が注目されている. oxy-fuel 燃焼法とは酸化剤として 純酸素を用い，燃焼器の過熱を抑制するために燃焼ガスの一部を再循環させる燃焼法で，水の凝縮のみで簡便に $\mathrm{CO}_{2}$ の回収を実現する(1). しかしこの手法では，燃焼器内の $\mathrm{CO}_{2}$ 濃度が高くなり燃焼が不安定化してしまう.

そこで本研究では，燃焼安定性向上のために触媒燃焼による保炎を考えた．触媒燃焼を前段階に導入すると， 触媒燃焼により予混合気が予熱されると同時に反応性の高い中間生成物が生成され，それらが触媒下流側の火炎 に供給されることで燃焼の安定化が期待できる. しかし，oxy-fuel 燃焼法のような高濃度 $\mathrm{CO}_{2}$ 中での触媒燃焼を 用いた二段燃焼の燃焼安定性については未だに明らかになっていない部分が多い. そのため, 本研究では高濃度 $\mathrm{CO}_{2}$ 中における触媒を用いた二段燃焼の燃焼安定性を明らかにすることを目的として実験と数值計算の両面から 調査を行った.

\footnotetext{
${ }^{* 1}$ 学生員, 慶應義塾大学大学院 理工学研究科

*2 正員, 慶應義塾大学（广223-8522 神奈川県横浜市港北区日吉 3-14-1）

E-mail: toshinori.nagai@z6.keio.jp
} 


\section{2. 实鋧方法}

実験装置の概略図を図 1 に示す. 本実験には内径 $5 \mathrm{~mm}$, 外径 $6 \mathrm{~mm}$, 長さ $30 \mathrm{~mm}$ の白金触媒円管を用いた. そ して, 触媒の上流側にはセラミックハニカムを設置し, 触媒とセラミックの外側を内径 $6 \mathrm{~mm}$, 外径 $8 \mathrm{~mm}$ の石英 管で覆った. 触媒円管内には $\mathrm{CH}_{4} / \mathrm{O}_{2} / \mathrm{CO}_{2}$ 予混合気を流し，触媒円管外側には $\mathrm{O}_{2} / \mathrm{CO}_{2}$ 混合気を流速 $0.2 \mathrm{~m} / \mathrm{s}$ で流し た. ここで混合気中の $\mathrm{O}_{2}$ と $\mathrm{CO}_{2}$ の体積流量比はいずれも 30:70 とした. そして触媒燃焼を持続させると同時に触 媒円管の下流側に火炎を形成させ, $\mathrm{CH}_{4} / \mathrm{O}_{2} / \mathrm{CO}_{2}$ 予混合気の流速 $V$ と当量比 $\phi$ を変化させることで触媒燃焼および その下流の火炎の安定限界を測定した。 さらに，触媒上流端から $2 \mathrm{~mm}$ の位置に R 型熱電対を設置し，触媒壁面 温度を測定した。.また, 比較のために $\mathrm{CH}_{4} / \mathrm{O}_{2} / \mathrm{N}_{2}$ 予混合気(触媒円管外側は $\mathrm{O}_{2} / \mathrm{N}_{2}$ 混合気)の場合でも同様の実験を 行った．触媒燃焼消炎時には触媒表面に化学種が被覆した状態になるため, 繰り返し実験を行うと次第に触媒の 反応性が低下していく，そこで, 実験の再現性を確保するために, 各測定前に $V=1.0 \mathrm{~m} / \mathrm{s}, \phi=2.0$, 酸化剂中 $\mathrm{O}_{2}$ 濃度 50 \%にて触媒燃焼を行い, 反応性の高い状態を 3 分間維持することで触媒表面の熱処理を行った.

\section{3. 数值計算方法}

Ansys Fluent14.0を用いて触媒然焼とその下流の気相燃焼のシミュレーションを行った. 用いたモデルは二次 元軸対称モデルであり，その概略図を図 2 に示す，座標の原点は触媒上流のセラミックハニカム領域の上流端中 心軸上の点とした. 気相反応には化学種 18 種 58 段の素反応モデル(2), 表面反応には化学種 11 種 24 段の素反応 モデル(3)を用いた. 固体内熱伝導やふく射伝熱も考慮した. ふく射モデルには DO モデルを用い，混合気の吸収 係数の算出に WSGG モデルを用いた。

また, 実験と同様に比較のために $\mathrm{CH}_{4} / \mathrm{O}_{2} / \mathrm{N}_{2}$ 予混合気(触媒円管外側は $\mathrm{O}_{2} / \mathrm{N}_{2}$ 混合気)の場合でも同様の実 験を行った.

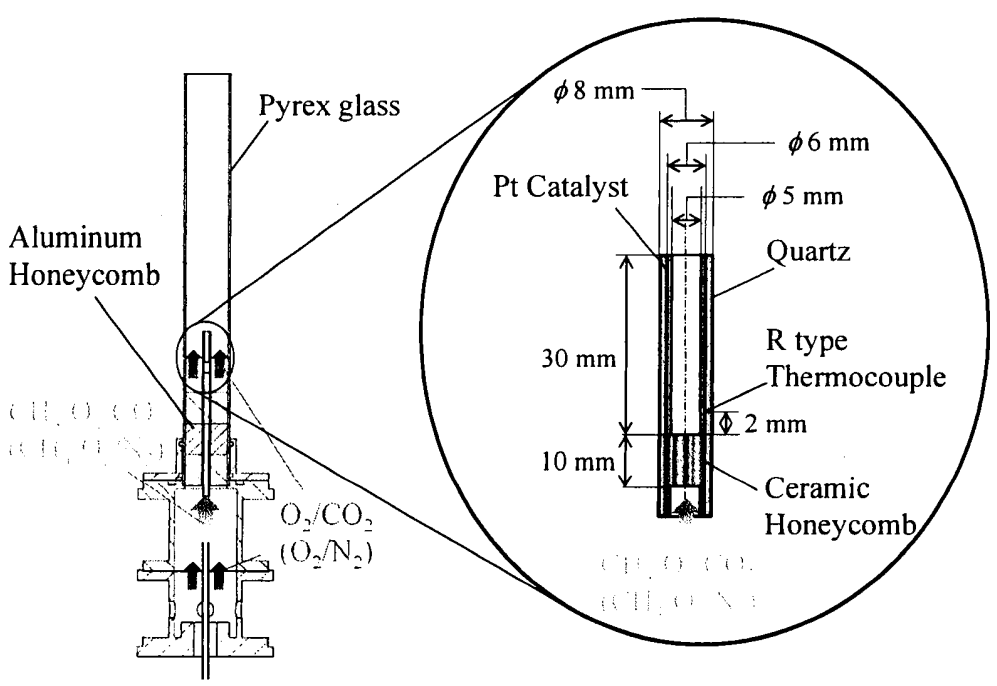

Figure 1 Schematic diagram of appratus

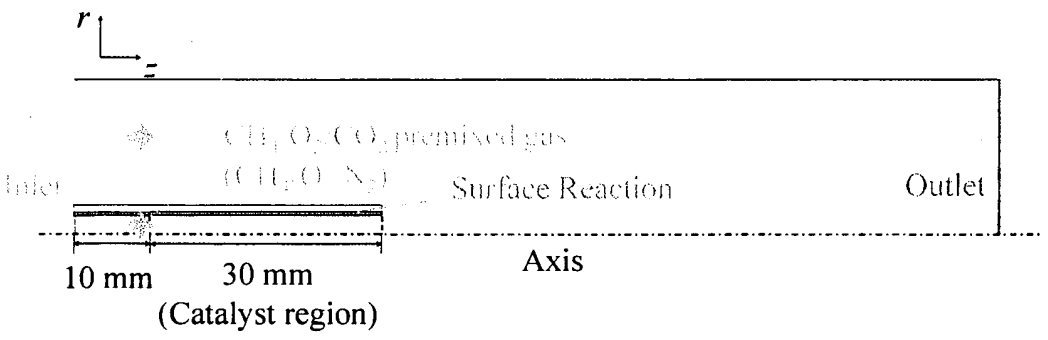

Figure 2 Schematic diagram of numerical calculation model 


\section{4. 結果・考菠}

\section{$4 \cdot 1$ 安定限界}

触媒円管下流の火炎の吹き飛び限界と触媒燃焼の安定限界を図 3 に示す．なお，火炎の吹き飛び限界について は比較のために, 触媒燃焼を導入しない場合として触媒の代わりにステンレス管を設置して実験を行った結果も 同時に示している. 図 3 より $\mathrm{CH}_{4} / \mathrm{O}_{2} / \mathrm{CO}_{2}$ 予混合気の場合の方が $\mathrm{CH}_{4} / \mathrm{O}_{2} / \mathrm{N}_{2}$ 予混合気の場合よりも火炎の吹き飛び 流速值は小さくなり，触媒燃焼の安定領域も小さくなっていることがわかる. これは主に $\mathrm{CO}_{2}$ の比熱が $\mathrm{N}_{2}$ の比 熱よりも大きいために温度が低下することが原因と考えられる.また, 気相反応においては $\mathrm{CO}_{2}$ が燃焼反忘に重 要な役割を果たすラジカルと反応し, 消費してしまうということも安定性低下の原因の一つと考えられる.また, 火炎の吹き飛び限界を見ると，いずれの予混合気の場合でも触媒燃焼を導入した場合は触媒燃焼を導入しない場 合に比べて当量比が比較的小さいときは吹き飛び限界が小さくなるが，当量比が大きくなると吹き飛び限界が大 きくなる．これは，当量比が小さい場合には触媒燃焼によって反応物が消費されてしまうために触媒燃焼を導入 することによって吹き飛び流速值が小さくなってしまうが，当量比が大きくなると触媒燃焼で反応物が消費され ても十分な量が火炎に供給されることに加え, 触媒燃焼による予混合気の予熱や CO などの中間生成物の生成に よって火炎の安定性が向上するためと考えられる. また, 図 3 の $\mathrm{CH}_{4} / \mathrm{O}_{2} / \mathrm{CO}_{2}$ 予混合気の触媒を入れた場合の火炎 の吹き飛び限界を見ると $\phi \geq 18$ の高当量比のとき，触媒燃焼が消炎してしまい火炎の吹き飛び流速值が触媒を入 れない場合と近い值になっている．このことからも，触媒然焼が火炎の吹き飛び流速值の増大に寄与しているこ とがわかる。

\section{$4 \cdot 2$ 数值計篎結果}

次に数值計算結果を用いて考察を行う. $V=1.0 \mathrm{~m} / \mathrm{s} ， \phi=5.0$ のときの触媒壁面温度を図 4 に触媒壁面温度分布 を示す. また，図 5 に全体の温度分布を示す. 図 4 よりこの条件の場合は触媒燃焼によって壁面温度が触媒を導 入しない場合に比べて最大で $400 \mathrm{~K}$ ほど大きくなっており，触媒燃焼の有無により予混合気を予熱する壁面の温 度に大きな差が現れることがわかる．また，触媒を導入した場合と導入しない場合のいずれの場合でも下流で壁 面温度が増加しており，これは下流側の火炎からの熱伝導が原因と考えられる.さらに, $\mathrm{CH}_{4} / \mathrm{O}_{2} / \mathrm{CO}_{2}$ 予混合気の 場合と $\mathrm{CH}_{4} / \mathrm{O}_{2} / \mathrm{N}_{2}$ 予混合気の場合を比較すると, 図 4 と図 5 のいずれの図においても $\mathrm{CH}_{4} / \mathrm{O}_{2} / \mathrm{CO}_{2}$ 予混合気の場合 の方が全体的に温度が低くなっていることがわかる．これは $\mathrm{CO}_{2}$ の比熱が $\mathrm{N}_{2}$ の比熱と比べて大きいことが主な 原因と考えられる. また，図 5 から実際に触媒燃焼を導入した場合は予混合気が予熱されていることがわかる.

次に, $V=1.0 \mathrm{~m} / \mathrm{s}, \phi=5.0$ のときの触媒燃焼によって生成される中間生成物である CO のモル分率分布を図 6 に示す. 図 6 より触媒燃焼によって $\mathrm{CO}$ が生成し下流の火炎に供給されていることがわかる. またいずれの予混 合気においても触媒燃焼を導入した場合は触媒を導入しない場合に比べて火炎部分での CO モル分率が小さくな っている. これは以下のように考えられる. 触媒燃焼を導入すると触媒燃焼によって燃料が消費されるために, 火炎部分では触媒燃焼を導入しない場合よりも燃料が希薄になる．さらに図 5 より触媒燃焼を導入するとわずか に触媒燃焼を導入しない場合に比べて火炎温度が低下している，以上のことから，触媒燃焼を導入すると火炎部 分においては燃料過濃でかつ高温条件の場合に生成量が増加する CO の生成量が減少すると考えられる.

以上より，触媒燃焼を導入することにより，予混合気が予熱されると同時に中閒生成物が火炎に供給されるこ とが数値計算によっても示された. さらに, $\mathrm{CH}_{4} / \mathrm{O}_{2} / \mathrm{CO}_{2}$ 予混合気の場合の方が $\mathrm{CH}_{4} / \mathrm{O}_{2} / \mathrm{N}_{2}$ 予混合気の場合よりも 予混合気の予熱が小さく，中間生成物の供給も小さいために図 3 において触媒燃焼を導入した場合と導入しない 場合での吹き飛び流速值の差が小さくなると考えられる. 


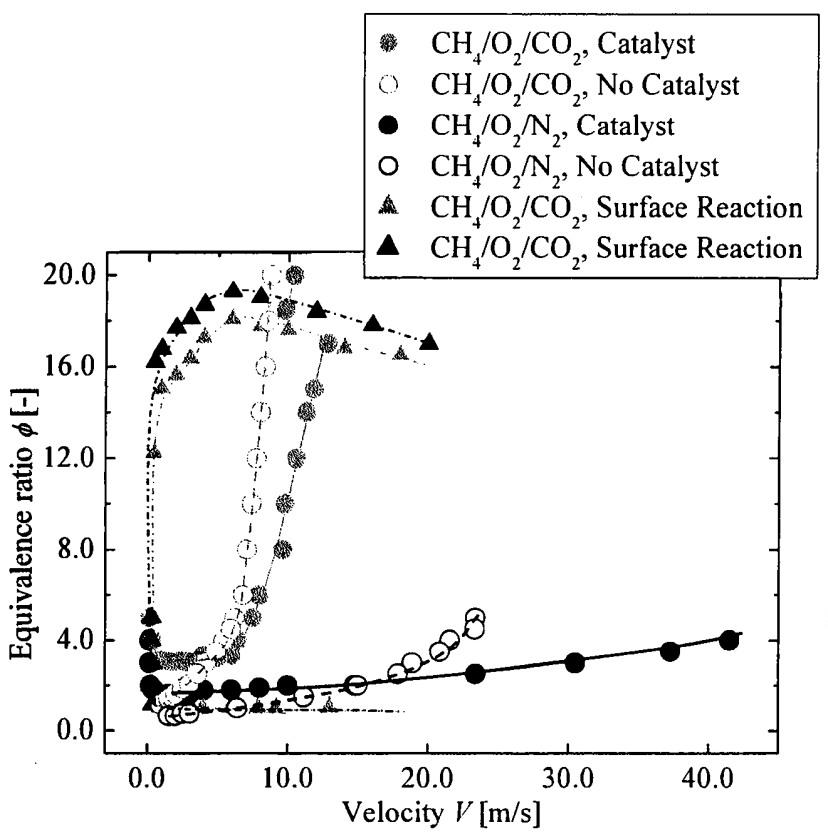

Figure 3 Blow off limit and extinction limit of catalytic combustion

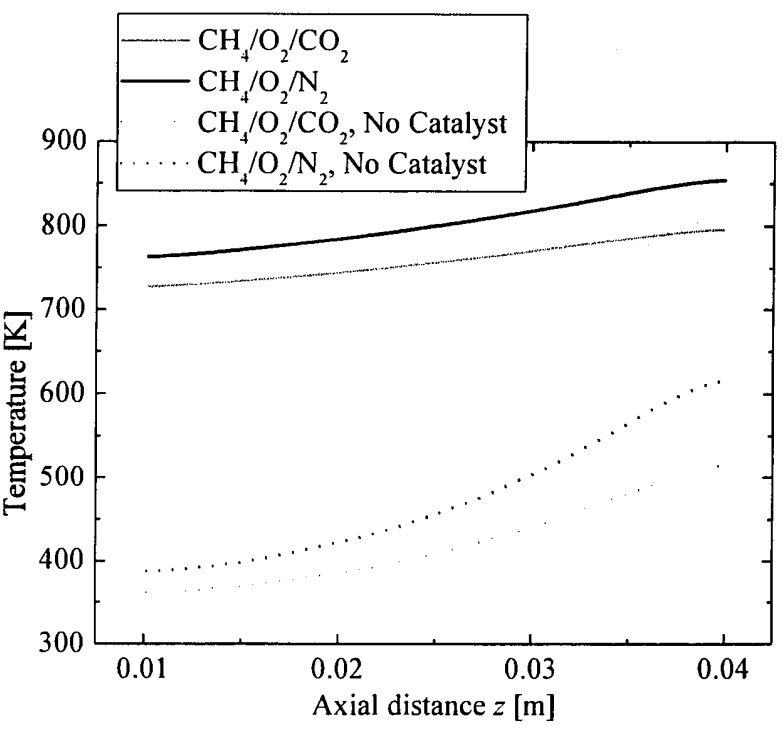

Figure 4 Surface temperature distribution

$$
(V=1.0 \mathrm{~m} / \mathrm{s}, \phi=5.0)
$$

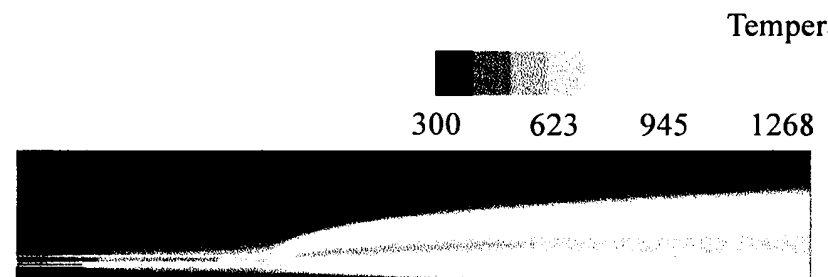

(a) $\mathrm{CH}_{4} / \mathrm{O}_{2} \mathrm{CO}_{2}$

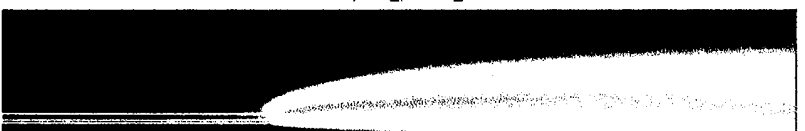

(c) $\mathrm{CH}_{4} / \mathrm{O}_{2} / \mathrm{CO}_{2}$, No catalyst

\section{1.}

$1590 \quad 1913 \quad 2235 \quad 2450$

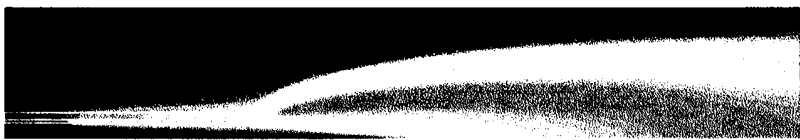

(b) $\mathrm{CH}_{4} / \mathrm{O}_{2} / \mathrm{N}_{2}$

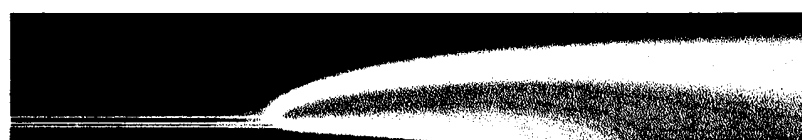

(d) $\mathrm{CH}_{4} / \mathrm{O}_{2} / \mathrm{N}_{2}$, No catalyst

Figure 5 Temperature distribution $(V=1.0 \mathrm{~m} / \mathrm{s}, \quad \phi=5.0)$

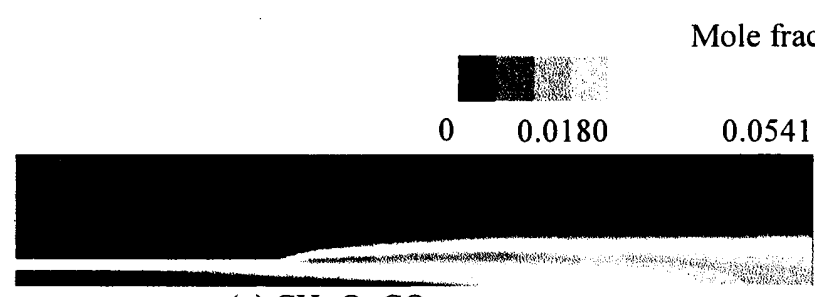

(a) $\mathrm{CH}_{4} / \mathrm{O}_{2} \mathrm{CO}_{2}$

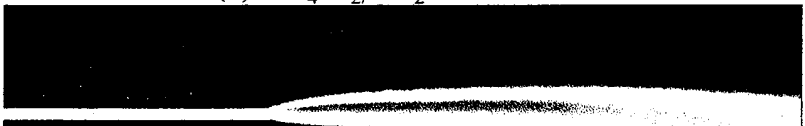

(c) $\mathrm{CH}_{4} / \mathrm{O}_{2}, \mathrm{CO}_{2}$, No catalyst (b) $\mathrm{CH}_{4} / \mathrm{O}_{2} \mathrm{~N}_{2}$

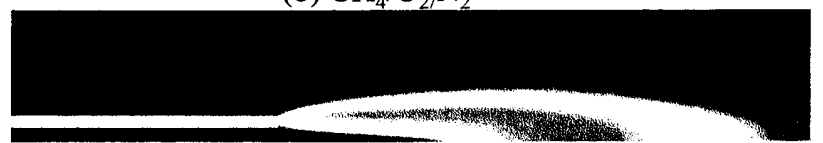

(d) $\mathrm{CH}_{4} / \mathrm{O}_{2} / \mathrm{N}_{2}$, No catalyst

Figure 6 Distribution of mole fraction of $\mathrm{CO}(V=1.0 \mathrm{~m} / \mathrm{s}, \quad \phi=5.0)$ 


\section{5.結调}

$\mathrm{CO}_{2}$ 排出量削減対策として注目される oxy-fuel 燃焼法では燃焼ガスを再循環させるために燃焼器内の $\mathrm{CO}_{2}$ 濃度 が大きくなり，燃焼が不安定化する.そこで本研究では燃焼安定化のために燃焼の前段階に触媒燃焼を導入した. そして, 高濃度 $\mathrm{CO}_{2}$ 中での触媒を用いた二段燃焼の安定性を明らかにするために実験と数值計算を行い以下の知 見が得られた。

(1)比較的低当量比の条件下では触媒燃焼を導入すると触媒燃焼を導入しない場合に比べて，触媒燃焼によって反 応物が消費されてしまうために火炎の吹き飛び流速值が小さくなった.

(2)比較的高当量比の条件下になると触媒燃焼を導入することにより，触媒燃焼によって予混合気が予熱されると 同時に反応性の高い中間生成物が生成され，火炎に供給されることで触媒燃焼を導入しない場合に比べて火炎の 吹き飛び流速值が大きくなった.

\section{文}

(1) IPCC, Carbon dioxide capture and storage, IPCC special report (2005).

(2) R.J.Kee et al., A Fortran computer program for modeling steady laminar one-dimensional premixed flames, Sandia National Laboratories Report, (1991)SAND85-8240.

(3) O.Deutschmann et al., Numerical modeling of catalytic ignition, Proc.Combust. Inst., Vol.26(1996), pp1747-1754. 